\title{
Modelling the Mechanical Integrity of Generic Solid Oxide Cell Stack Designs Exposed to Long-term Operation
}

\author{
T. T. Molla ${ }^{1}$, K. Kwok ${ }^{1}$, H. L. Frandsen ${ }^{1 *}$ \\ ${ }^{1}$ Technical University of Denmark, Department of Energy Conversion and Storage, \\ Frederiksborgvej 399, P.O. Box 49, Building 779, 4000 Roskilde, Denmark \\ ["]Corresponding author: hlfr@dtu.dk
}

\begin{abstract}
Thermal cycling and creep in metallic interconnects during operation of solid oxide cell (SOC) stacks could cause contact losses in the interface between the interconnect and cells. The magnitude of stress and its distribution within the SOC stack depends on the overall design of the stack and the operating conditions. In this study, stresses in different types of generic SOC stack designs caused external loading and temperature variations through long-term operation are investigated. The investigation includes stack designs with and without contact components combined with machined (cross-shaped) or pressed (corrugated) interconnects. Two different generic temperature profiles in the stacks are considered. Special focus is given to stresses that can cause possible delamination of the interconnect from the cell that subsequently leads to loss of electrical contact. It is found that too rigid designs cause high stresses and creep in the interconnects, and so-called stress reversal will cause delamination between interconnect and cell during shut-down. Furthermore, the study also presents the effect of SOC stack design and/or thermal gradient on the magnitude of in-plane stresses in the cells. Here it is found that it advantageous to cool the stack primarily with convection, as this causes a linear thermal profile and much lower stresses than if cooling is relying on conduction in the solids, as this causes a thermal gradient in several directions.
\end{abstract}

Keywords: Solid Oxide Fuel Cells, Solid Oxide Electrolysis Cells, Loss of contact, Failure of cells, Creep, Finite Element Modeling, Long-term operation

\section{Introduction}

Solid oxide fuel cells (SOFCs) are electrochemical energy conversion devices that use fuels (e.g. hydrogen) and oxygen to produce electricity. They can also be operated in reverse mode as solid oxide electrolysis cells (SOECS) to produce fuels by using electrical energy. SOFCs and SOECs are generally referred to as solid oxide cells (SOCs). The operation of SOCs relies on electro-chemical reactions taking place within the electroactive ceramic cell layers, i.e. anode, electrolyte and cathode at high temperature (typically above $600^{\circ} \mathrm{C}$ ). Technologically, planar SOCs are stacked together to enhance the output (power or fuel), and thus the stack is designed in a way to facilitate the supply of gases (fuel, feedstock, air), collect electrical current and ensure a steady and reliable operations. The SOC stacks therefore consist of standard repeating units (SRU), i.e. the cell together with other auxiliary components like interconnect, manifolds, spacers, sealings, etc., for an example see Figure 1.

This is the author manuscript accepted for publication and has undergone full peer review but has not been through the copyediting, typesetting, pagination and proofreading process, which may lead to differences between this version and the Version of Record.

Please cite this article as doi: 10.1002/fuce.201800081

This article is protected by copyright. All rights reserved. 
There are various types of planar SOC stack designs used by different developers of the SOC technology [1-5]. Some designs involve contact layers between the interconnects and cells [2], whereas others rely on profiled interconnects or both to facilitate the flow of gases within the stack $[1,6,7]$. Some developers use metallic interconnects, where the channels are machined or etched from a larger piece [8], while others prefer shaped metal foil interconnects (e.g. using hydro-forming or mechanical pressing) $[1,6]$. Besides there is also recent development of monolithic stacks, which also utilize thin ceramic interconnects [9].

However, during operation of SOCs, the SOC stack experiences local heating (i.e. due to the electrochemical reactions and Ohmic heating) that can generate thermo-mechanical stresses [4]. These stresses could cause permanent deformations of the metallic interconnect, which may lead to electrical contact loss at the interface with the electrode $[2,6,10]$. The metallic interconnect is one of the dominant structural component in planar SOCs, and thus its deformational behavior significantly affects the distribution of stresses throughout the SOC stack [5]. Therefore, the design of the interconnect, in particular, and that of the stack in general has a significant impact on the mechanical integrity of SOC stacks.

There are a number of reported works on analyzing the thermo-mechanical stresses within the SOC stack at its operational conditions $[2-5,7,10,11]$. Some of the most extensive studies are reported by Nakajo et $a l$. $[2,3,10,11]$ and Peksen et $a l .[4,12,13]$. Nakajo et al. used thermo-mechanical models of an SRU of a SOFC stack to analyze its mechanical integrity at different operation scenarios. Nakajo et $a l$. points out that "irreversible deformation due to rate-independent plasticity and creep during prolonged operation can amplify the detrimental effects of thermal and electrical load cycling", by studying creep of the anode $[3,11]$. Nakajo et al. were able to show increase in probability of failure of the cells during transient operations and a possibility of buckling of metallic interconnects due to plastic deformation $[2,10]$, although creep was not considered in these studies.

Similarly Greco et $a l$. showed that the probability of failure of the cells in an operating stack decreases over time due to relaxation of stresses, and the probability of failure peaks at the shifts between operation point [7]. Peksen et $a l$. and Pianko-Oprych et $a l$. also made an extensive study on planar SOFC stack involving computational fluid dynamics together with structural mechanics shedding light on the transient thermal behavior of the stack [4] and the correlation between stress and operational voltage in the SOFC [14].

The findings through the different studies are related to a specific type of SOC stack design and a specific set of operational parameters and resulting thermal profile. The stress level and effects of design is thus hard to study directly and comparison challenging.

The objective of the present work is to demonstrate that 1) compliance in an SOC is rather detrimental for integrity and 2) that the stresses from thermal expansions are less dependent on the magnitude of the thermal gradients and far more dependent on the shape of the temperature field. This is done by investigating the thermal stresses in four different types of generic SOC stack designs exposed to long-term operation, accounting for the elastic as well as creep behaviors of all the parts within the stack. The study involves generic stack designs with and without contact components combined with metallic interconnects, which has cross-shaped (from machining / etching) or corrugated (shaped metal foils) shape under similar operating conditions. Special focus is given to the vertical normal stress that can possibly cause delamination between the interconnect and the cell, which subsequently leads to loss of electrical contact. In addition, the magnitude of in-plane stresses in the fuel electrode support is investigated. The effect of two generic temperature profiles are investigated for the purpose of illustrating that the shape of thermal field is more detrimental for the stress level than the magnitude of the temperature gradients. For this purpose, two generic thermal profiles are chosen, i.e. one for pure conductive and one for pure convective heat transfer. The investigation is performed by numerical modelling of the SRU using a commercial finite element (FE)

This article is protected by copyright. All rights reserved. 
software ABAQUS ${ }^{T M}$. To achieve the long-term simulations, the SRU models relies on so-called homogenized representation of the interconnect structure $[6,15]$.

\section{Studied stack designs}

The analysis involves four types of generic SOC stack designs. The cross-sectional views of the standard repeating units based on corrugated and cross-shaped interconnects with and without contact components are shown in Figure 2 (a) to (d). The designs are referred to as (a) CIC: stack design based on corrugated interconnect without contact layer, (b) CIC_c: stack design based on corrugated interconnect and having contact layers, (c) XIC: stack design based on cross-shaped interconnect without contact layers and (d) XIC_c: stack design consisting cross-shaped interconnect together with contact layers.

The studied stacks are assumed to be rectangular with an outer cross-sectional area of $120 \mathrm{~mm} \times 120$ $\mathrm{mm}$. The width of the spacer and sealing area is of $10 \mathrm{~mm}$, with an active area of $100 \mathrm{~mm} \times 100 \mathrm{~mm}$. The thickness and materials used for the different layers in the model are summarized in Table 1.

The vertical manifold holes for gas transport varies significantly between the different stack designs, and this information is rarely public. These holes may introduce local stresses due to the thermal interaction with feedstock gasses. This effect is however not the focus of the current investigation, and holes will only affect the stresses in the active area moderately. This study focus on the loss of contact occurring in the active area, and including the holes will thus not change the conclusions of this work, why they have been omitted.

Likewise, have failure in the sealings not been studied in this work (although they are important for the integrity as well). The glass sealings are rather thin (from 20 to a few $100 \mu \mathrm{m}$ ) and are typically placed between the cells, interconnects and spacers to prevent mixing of gasses. The local stresses in the sealings are thus not used in the analysis, and they only influence the results via their contribution to the average stiffness of the manifold area. Therefore, the sealings are not explicitly represented in the current model, and as they are thin the stiffness of the manifold area is assumed to be that of steel of the spacers and interconnect alone.

The contact layers, when present, are assumed to be foams of spinels (based on e.g. Co and $\mathrm{Mn}$ ) on the air side and $\mathrm{Ni}$ on the fuel side having $90 \%$ porosity. For the ceramic foams (spinel) lower creep rates are expected, and as creep material parameters for these materials are not available in the literature, we have also applied the creep properties of 8YSZ to the ceramic foams while correcting for the porosity.

\section{Simulation of long-term operation}

\subsection{Variations over time}

To study the mechanical response during long-term operation, the following simplifications have been made:

i) The stress variation through the cell fabrication in the oxidized conditions is neglected. The reason is that the stack can practically be assumed to be stress free after reduction due to accelerated creep [16]. The accelerated creep occurs during the reduction, and it is shown that Ni-YSZ anode supports deforms a rate $\sim 10^{4}$ faster than during operation due mobility of the Ni network [16]. All stresses in the half-cell (support, fuel electrode and electrolyte) are relaxed and practically go to zero through the reduction. This has been confirmed by in-situ measurement of the residual stresses $\mathrm{X}$-ray diffraction (publications are in preparation).

ii) A SOC stack will most likely be operated under varying current loading throughout the lifetime of the stack. Whenever the stack is under operation, temperature variations will generate thermal stresses, which deform the different materials plastically, i.e. through high- 
temperature creep. The plastic deformations will accumulate over time and the magnitude of plastic deformation increments depend on the stress level. Here we consider a representative average thermal expansion to represent the different thermal expansions due to the current load variations.

Based on the above assumptions, the following analysis steps are thus defined to simulate the temperature and loading profiles for the stack concepts:

1) The stack is assumed to be stress-free at the reduction temperature of $900{ }^{\circ} \mathrm{C}$ because of the accelerated creep (see above),

2) A total vertical force of $7200 \mathrm{~N}(\approx 720 \mathrm{~kg})$ is applied by constant ramping over 1 hour,

3) The condition in Step 2 is kept for 2 hours,

4) The relevant temperature field is applied to the stack over 1 hour while retaining the load,

5) The stack is kept for 40,000 hours of operation with a constant temperature field from Step 4 ,

6) The stack is cooled down to room temperature in 1 hour.

\subsection{Spatial variation of temperature}

The temperature profile inside a SOC stack depends on many parameters, such as flow conditions, gas compositions, ambient conditions (boundary conditions), current and thus also amount of reactions, channel and manifold geometry - i.e. design of the stack etc. The combination of all these will eventually lead to a thermal profile, which has great impact on the mechanical behavior of the stack. The different stack designs will thus under same flow rates provide slightly different thermal profiles, due to the geometry of the flow field. This, in turn, can be coupled with the mechanics to model the deformational behaviors of the different layers in SOC stack through thermal stresses, which would differ slightly.

However, the point of this work is to compare the mechanical response in different types of generic stack designs exposed to the same temperature distributions across the SOC stack to be able to clearly compare the mechanical response. Thus, simulation of heat transfer for the different stack designs based on a specific set of operational parameters, cell performance, boundary conditions, geometry, etc. has been avoided.

Furthermore, it is a purpose of this work to clearly show which type of thermal profile must be avoided and which should be preferred during operation due to the resulting thermal stresses. As will be shown; the shape of the thermal profile heavily influences the stress level and the magnitude of the thermal gradients, less. This applies to both the in-plane stress level primarily influencing the failure of the cells, and the vertical stress level primarily influencing the loss of contact.

To illustrate this, two types of distinct temperature profiles that represent distinct scenarios are obtained and imposed on the repeating units of the SOC stack; I) from pure conduction of heat through the solids of the stack, and II) from pure convection of gasses blown through the stack. In a real stack both transport phenomena occur and their influence is governed by the amount of forced convection of air blown through the stack. Distribution of heat along the channels (free surfaces) by radiation is negligible at lower operation temperatures $\left(750-850^{\circ} \mathrm{C}\right)$.

Since Fourier's law for heat transport is a linear partial differential equation (PDE), the temperature distribution in a stack is more or less a linear combination of the two thermal fields from convection and conduction (superposition principle). The elastic thermal stress in the stack will thus also be a linear combination of the stress field of the two thermal profiles, as elastic stress profiles also can be linearly superposed. The amount of forced convection of air through the stack determines the 
governing heat transport mechanisms, and it can thus be used to minimize the stress level in the stack, based on the recommendations in this work.

In both simulations, heat from the electrical reaction is assumed to be generated equally in the active area (no bias from e.g. lower ASR at higher temperatures). The two temperature distributions are simulated by:

I) Pure conduction: The generated heat is dissipated along the perimeter at a rate such that a maximum of $50{ }^{\circ} \mathrm{C}$ temperature difference between the center and edges of the stack is achieved. The boundary condition is thus a constant temperature along the perimeter of the stack. The temperature span is chosen to be between 750 and $800{ }^{\circ} \mathrm{C}$ as this is in the vicinity of typical SOC stack operation temperatures. This kind of temperature profile across the surface of the SOC stack could represent a scenario, where there is no cooling, e.g. by blowing air through the stack, forcing heat conduction to be the dominant mechanisms for heat dissipation.

II) Pure convection: The generated heat is heating the air gradually as it is flowing through the stack. This results in a linear temperature profile across the stack. The amount of generated heat can be balanced by the amount of air blown through the stack. Here a ratio is chosen to achieve a linear thermal profile a maximum difference of $100^{\circ} \mathrm{C}$ in the flow direction. The direction of the linear temperature profile depends on operating mode (SOFC or SOEC). E.g., excess heat needs to be removed in the case of SOFC and vice versa.

In the two thermal profiles the same thermal gradient is approximately obtained $\left(\sim 50^{\circ} \mathrm{C}\right.$ per $\left.5 \mathrm{~cm}\right)$, but temperature profiles are quite distinct, as shown in Figure 3 (I) and (II). Both temperature profiles have been simulated using Comsol Multiphysics.

\section{Numerical modeling}

\subsection{Finite element model}

The analyses were carried out using FE modeling of the different stack designs presented in Section 2 to evaluate the corresponding stresses from the long-term operation of SOCs presented in Section 3. Since the SRU with temperature profile $I$ is symmetrical along $x$ - and $y$-axes, a quarter of the stack geometry is used in the modeling, see Fig 3 (I). Whereas in the case temperature profile II, the symmetry along the $\mathrm{x}$-axis requires half of the stack geometry is considered in the FE modeling, see Fig 3 (II).

Due to the repetitiveness of the SRUs in the stack, the top and bottom surfaces of the SRUs should deform similarly. It is however rather difficult to ensure that the extension of the stack along the zdirection are the same across the stack (a very stiff frame would be needed). We thus here assume that the stack is free to rotate according to the thermal expansions. The SRU may thus deform to a wedge, i.e. the two end planes deform similarly but may rotate to balance the internal and external forces. It is also assumed that the stack planes remain plane, because the stacks are typically pressed together by two rigid plane end-plates, which do not allow for any distortion out of plane, and is a common assumption [3,11]. This can be modelled as described by Nakajo et al., where the flatness of the top and bottom surfaces are ensured by using a linear function on a multi-point constraints in ABAQUS [11].

For temperature profile I, the dual symmetry results in that the SRU top and bottom plane only moves along the $z$-axis. For temperature profile II the top and bottom planes will translate along the $z$-axis but also rotate due to the higher thermal expansion in the warmer side of the stack. The difference in displacement along the z-axis, $U_{z}^{p}$, between the corresponding nodes on the bottom and top surfaces of the SRU can thus be written as a simple linear function of the position along the 
$x$-axis, see Fig 3(II). Here this is expressed by using the z-displacements of two reference nodes at $x=$ $-L\left(U_{z}^{1}\right)$ and $x=L\left(U_{z}^{2}\right)$ as:

$$
U_{z}^{p}(x)=\left(\frac{U_{z}^{2}-U_{z}^{1}}{2 L}\right) \cdot x+\frac{U_{z}^{2}+U_{z}^{1}}{2}
$$

The vertical boundaries of the SRUs are unconstrained in the models.

The geometry for each layer is meshed using 3D stress elements (C3D8 in ABAQUS term) of size 2.5 $\mathrm{mm}$ in the plane of the stack and a minimum of 5 and maximum of $80 \mu \mathrm{m}$ along the thickness direction. In ABAQUS, the temperature profile across the stack is applied using an analytical mapped field.

\subsection{Material behavior of homogenous layers}

The total deformational strain, $\varepsilon^{\text {tot }}$, in all layers in the stack is assumed to be the sum of elastic strain, $\boldsymbol{\varepsilon}^{e l}$, thermal strain, $\boldsymbol{\varepsilon}^{\text {th }}$, and viscoplastic strain, $\boldsymbol{\varepsilon}^{\mathrm{vp}}$, as:

$$
\varepsilon^{t o t}=\varepsilon^{e l}+\varepsilon^{t h}+\varepsilon^{v p}
$$

The elastic strain tensor can be modeled by using Hooke's law as:

$$
\varepsilon^{e l}=\frac{1+v}{E} \sigma-\frac{v}{E} \operatorname{tr}(\sigma) l
$$

where $E$ and $v$ represent the Young's modulus and Poisson's ratio of each layer at the corresponding temperature. $\sigma$ is the stress tensor and, $I$, represents a unit matrix. $t$ is short for the trace of the tensor.

The thermal strain in each layer can be determined using its coefficient of thermal expansion, $\alpha$, and the rate of change in temperature, $T$ over time, as:

$$
\dot{\varepsilon}^{\text {th }}=\alpha \dot{T} \mathbf{I}
$$

where the dot above notates the time derivative of the quantity. The viscoplastic strain rate tensor (secondary creep rate), $\mathbb{S}^{p}=d \varepsilon^{v p} / d t$, in the layer at a stress, $\boldsymbol{\sigma}$, is given by $[6,16]$ :

$$
\dot{\boldsymbol{\varepsilon}}^{v p}=\frac{3}{2} A\left(\frac{\sigma_{e q}}{\sigma_{0}}\right)^{n-1} \frac{\sigma^{\prime}}{\sigma_{0}}
$$

Here, $A, \sigma_{0}, n$, are creep parameters of each layer, provided in Table 2. $\sigma^{\prime}$ is the deviatoric stress tensor and, $\sigma_{e q}$, is the von Mises equivalent stress given by:

$$
\sigma_{e q}=\sqrt{\frac{3}{2} \sigma^{\prime} \cdot \sigma^{\prime}}
$$

\subsection{Homogenization of interconnects}

The many features in the interconnect, even in a SRU, makes long-term simulation of the creep deformations in the interconnect a computational very heavy task. For computational efficiency, homogenization of the interconnects is conducted [6]. In homogenization the mechanical behavior of the complex repeating geometry is represented by a homogeneous anisotropic equivalent material, see Figure 4. By an equivalent material we here mean that it has equivalent deformational 
properties. In practice, the many geometrical features are removed and replaced by and easily meshed homogenous material.

Homogenization of the cross-shaped metallic interconnects is achieved by calculating the homogenized elastic parameters ( $E$ and $v$ ) as well as creep parameters ( $A$ and $n)$ using the analytical approach suggested by Kwok et al. [15].

Homogenization of the corrugated metallic interconnect, which has a more complex geometry, is done according to previous work [6]. In this the average or homogenized deformation of the corrugated interconnect is the sum of elastic strain, $\varepsilon^{e l}$, thermal strain, $\varepsilon^{\text {th }}$, and viscoplastic strain, $\varepsilon^{v p}$ as shown by Eq (2).

Here the homogenized elastic strain tensor, $\boldsymbol{\varepsilon}^{e l}$, is modeled using a homogenized stiffness tensor, $\boldsymbol{D}$, in which the non-zero components can be estimated using the homogenized stress and strain response during the elastic deformation of a representative unit cell of the interconnect [6]. The homogenized thermal strain in the interconnect is the same as Eq (3). However, the homogenized viscoplastic strain rate is given by [6]:

$$
\dot{\boldsymbol{\varepsilon}}^{v p}=\frac{1}{2} A\left(\frac{\sigma_{\text {eq }}}{\sigma_{0}}\right)^{n-1} \frac{\mathrm{M} \sigma}{\sigma_{0}} \circ \Gamma
$$

where, $\mathbf{M}$, is a square matrix with coefficients defining the anisotropy of the structure and, $\sigma_{e q}$, is the homogenized equivalent stress given by:

$$
\sigma_{e q}=\left(\frac{1}{2} \sigma^{\top} \mathbf{M}\right)^{\frac{1}{2}}
$$

The tensor, $\Gamma$, accounts for geometric non-linearities due to contact of the interconnect with the electrode surfaces [6].

The above model is implemented in ABAQUS through a user defined material (UMAT) subroutine. The material properties of corrugated metallic interconnects are calculated according to the technique presented in Ref [6]. The reference stresses, $\sigma_{0}$, in Eq (7) can be chosen arbitrarily to be equal to $1 \mathrm{MPa}$ in all materials [6].

All the material parameters at the respective temperatures used in the model are listed in Table 2. The tensors used in modeling the corrugated interconnect within the stack for a cell operating between 700 and $800{ }^{\circ} \mathrm{C}$ i.e. the homogenized stiffness tensor, $\boldsymbol{D}$, and anisotropy coefficients, $\mathbf{M}$, can be found in Appendix 1. Since the focus in this study is on long-term creep, the transient response from the non-linear geometric functions, $\Gamma$, are neglected by setting all the components in it to be 1.

\section{Results and discussions}

\subsection{Stresses in the interconnect cell interface}

In Figure 5 the normal or out of plane stress, $\sigma_{z z}$, at the center of the stack in the cell-interconnect interface throughout the operational cycle for the different stack designs exposed to temperature profile I is presented. The stress history for all the designs are seen to vary similarly over time. The maximum normal stresses in the cell-interconnect interface are identified at two states:

A) Compressive stresses when the temperature distribution is reached or at the beginning of the steady state operation (i.e. at the beginning of step 4) and 
B) Tensile stresses after cooling down to room temperature or at the end of step 6 .

The stresses at State $A$ influences the magnitude of the long-term creep during operation. The maximum tension at State B is chosen, as this will be the most critical for delamination between the cell and the interconnect.

The reason for this behavior is that the compressive stress in the z-direction in the center of the stack induces creep in the interconnect during the operation and the interconnect is compressed. During cooling of the stack and reduction of the thermal expansion, the compressed part of the interconnect must be stretched back to the original shape for it to remain in contact with the electrodes. This stretching with tensile stresses occurs through the brittle interfaces between the cell electrodes and the interconnects, and hence detachment (loss of contact) may occur. This depends on the amount of creep deformation and accompanying stresses [6]. The maximum vertical tensile stress is reached at room temperature after shutting down, i.e. State B, see Figure 5.

The stress is seen to vary significantly over the first 1000 hours, but the stress variation is limited after $\sim 15,000$ hours of operation.

\subsubsection{Stacks exposed to temperature profile I, conduction}

Representative stress, $\sigma_{z z}$, distributions across the surface the interconnect are shown in Fig. 6 and 7 for four different types of stack concepts exposed to temperature profile I. Because of symmetry, only a quarter of the interconnect is shown. The shown stress contours for the four different stacks in Fig. 6 are for State A whereas the contours in Fig. 7 are for State B.

As shown in Fig. 6, the maximum compressive stress, $\sigma_{z z}$, in all cases, occurs at the center of the stack, where there is larger thermal expansion. Generally, the compressive stress is lower for designs with contact components because the overall compliance and creep rate in the contact components are higher and stresses are thus relaxed faster. Comparison of the four design concepts show the smallest compressive stress occurs in the case of $\mathrm{CIC}_{-} \mathrm{c}$ or the stack design with corrugated interconnect having contact layers, see Fig. 6 , and it is found to be the most compliant design.

After 40,000 hours of operation, permanent creep strains are induced in the interconnect. Cooling from this state leads to the opposite stress distribution in State B as compared to State A. At State B, the compressive stress in the middle has been turned into tensile stress in all the cases, as shown in Fig. 7.

An additional effect occurring at room temperature is the lateral compression of the interconnect due to thermal expansion mismatch of the cells and the interconnect. The lateral compression of the interconnect leads to a vertical expansion due to the Poisson's effect, which could be the explanation for this opposite effect of the cross-shaped interconnect. Note that significant tensile stresses are observed in the case of stack designs involving cross-shaped interconnects.

A comparison of stresses at State A and B for all the stack designs exposed to the temperature profile $\mathrm{I}$ is shown in Fig 10 (a). The magnitude of stress is related to the creep rate of the interconnect (with its geometry), contact layers, and spacers. The stress is lower when the effective creep rate of the combination is faster, i.e. the more compliant stack designs. The combination of corrugated Crofer 22 APU with contact layers have the fastest creep rate, and hence maintain a low stress. At room temperature, the thermal expansion mismatch induces stress in addition to the permanent creep strain. Hence, different thermal expansion coefficient mismatch of the materials is another important factor.

This article is protected by copyright. All rights reserved. 


\subsubsection{Stacks exposed to temperature profile II, convection}

Similarly, the stress distributions in the cell-interconnect interface for the stack designs exposed to temperature profile II are shown in Fig. 8 and 9. Due the symmetry of the stack along x-axis, half of the inferface is shown. Fig. 8 shows the stress distributions at State $A$ (before operation) whereas Fig. 9 shows the stress distributions at State B (after cooling).

At the beginning of the steady-state operation, the stresses are relatively low compared to the stresses in temperature profile I. There is however a tendency for the maximum vertical compressive stresses, $\sigma_{z z}$, to occur at the cold edge, see Fig 8 . This is because, the gradient of thermal expansions, which makes the interconnect rotate around $y$-axis, while remaining flat. This results in compression of the left edge (where the temperature is lower). Comparison of the four stack concepts reveals once again that the least compressive stress occurs in the design having corrugated interconnect with contact layers.

After 40,000 hours of operation and cooling down to room temperature, the stresses are also very small compared to those from the exposure to temperature profile I. The stresses are primarily compressive and almost no tensile stress is observed in all cases, see Fig 9. For stacks exposed to a temperature profile II (convection), it is only the design that involves cross-shaped interconnect with contact layer that shows relatively small tensile stress, after the stack has cooled down to room temperature. This may be due to the presence of contact layers that is pressed by a relatively stiff interconnect, resulting in higher creep deformations and larger tensile stresses after cooling.

Even though the thermal gradients in temperature profile II are comparable as those of temperature profile I, the magnitude of normal stresses are significantly smaller in the case of stacks exposed to the linear temperature profile (temperature profile II). This shows the advantage of maintaining a linear thermal profile, e.g. by excessive forced convection during operation of SOCs.

A comparison of the stresses at State $A$ and $B$ for all the stack designs exposed to temperature profile II (convection) is shown in Fig 10 (b). Stack concepts involving corrugated interconnects are again found to result in lower stresses at both State A and B. This is true for both temperature profile I and II. The use of cross-shaped interconnect without contact layers in temperature profile II is also observed to cause significant stress at the beginning of steady state operation, see Fig 10 (b).

Depending on the rate of the shifts between operation points, time independent plasticity should be considered as well. While operating the stack smoothly the thermal field will change smoothly as well, and creep will continuously reduce the induced stresses. The faster the operation the less creep is able to relax the stresses and they become larger, and in some cases time-independent plasticity can occur. In the current study, it can be seen from Fig. 5 that the stresses do not reach beyond 20 $\mathrm{MPa}$ and the yield strength of Crofer $22 \mathrm{APU}$, is approximately $30 \mathrm{MPa}$ at $800^{\circ} \mathrm{C}[17,18]$. Thus, with the current generic designs, thermal profiles and operation rates time-independent plasticity is not relevant to consider.

From comparison of the magnitude of stresses on the metallic interconnect involving all the design concepts, see Fig 10 (a) and (b), two main conclusions can be drawn:

i) Significantly lower stresses are observed for stacks exposed to linear temperature profile from convective heat transport (temperature profile II) as compared to that of conductive heat transport temperature profile (temperature profile I). This is because the warmer interior of the stacks with temperature profile I are not allowed to expand freely in the vertical direction, but is constrained by the perimeter of the stack. This is not the case with temperature profile II, where 
the warm side of the stack is allowed to expand freely, due to the allowable rotation of the end plates (envisage the planes of the stack moving as an accordion).

ii) Significantly lower stresses are observed for the more compliant stack designs, i.e. the stack designs with corrugated interconnects results in far smaller stresses than those with cross-shaped interconnects. The CIC_c stack design is the most compliant and thus exposed to the smallest stress after cool down, and the XIC stack is the least compliant and thus exposed to the highest stresses after cool down. The reason is that the thermal expansions will induce higher stresses in the stiffer stack designs. This is less important when the interior of the stack is in compression through high temperature operation, but may become problematic during cool down, where the plastic deformations results in a stress reversal and tensile stresses between the brittle interface between electrodes and interconnects.

\subsection{In-plane stresses in the fuel electrode support}

As discussed in Section 3.1, the cell is assumed to be initially stress-free due to accelerated creep and consequent stress relaxation [19]. The thermal gradients across the stack will however induce an inplane stress.

Figure 11 shows the in-plane stress variation in the fuel electrode, for the stack design involving cross-shaped interconnect (XIC) at the beginning of steady state operation (State A), when it is exposed to temperature profile I and II. These stresses will induce creep in the cells through the operation period. As shown in Figure 11, the XIC stack exposed to temperature profile II shows significantly lesser stress at State $A$, which once again shows the advantage of the linear temperature distribution.

When the stack cools down to uniform temperature, the stresses from State A will reverse due to the creep of the cell. Also, the magnitude of stress will increase because of the thermal contraction mismatch of the remaining stack components during cooling. The maximum in-plane stress on the fuel electrode support thus occurs after cooling down the stack to room temperature (State B).

Figure 12 shows an example of distribution of in-plane stresses (maximum principal stress) on the fuel electrode for the XIC stack design exposed to temperature profile I and II after cooling down to room temperature (State B). As shown in Figure 12, the difference in the maximum in-plane stress at State $B$ between the two temperature profiles is minimal, although largest for thermal profile $I$ as at state $A$.

Figure 13 (a) and (b) show a comparison of the maximum in-plane stresses in the fuel electrode support for the four types of stack designs exposed to temperature profile I and II at State A and B respectively. At the beginning of steady state operation (State A), all stack designs exposed to temperature profile I show significantly higher stresses than those exposed to temperature profile II, see Figure 13 (a). The lower stress at State A are however also quite relevant, as the cell weakens with temperature [20]. The stress levels obtained here do however fall well below the measured strengths.

After cooling down to room temperature (State B), stress grow due to thermal expansion, but the difference due to temperature profiles is small for all cases, see Figure 13 (b). At State B, the fuel electrode support experiences a slightly higher in-plane stress for all designs, when temperature profile I is used. This is because of the larger creep deformations due to the higher stresses at steady 
state operating condition. Note here that the stack design involving corrugated interconnect with contact layers ( $\mathrm{ClC} \mathrm{C}_{-}$) is observed to generate lower in-plane stress on the fuel electrode support than the other design options at State A.

Comparison of the in-plane stresses on the fuel electrode support from all the design concepts, see Fig 13, shows that:

i) Temperature profile of the stack involving convective heat transfer (i.e. temperature profile II) is far gentler to the cell at operational conditions

ii) At room temperature, the mismatch of CTE's plays a significant role and results in the highest contribution to the stress level. The difference in the magnitude of stresses is less between temperature profile I and II, although temperature profile II provides the relatively smallest stresses.

\subsection{Design Recommendations}

In SOCs, a major part of the load is determined by thermal expansions and gradients thereof. Thus, if the SOC stacks are compliant to these expansions, the current findings indicate a greater chance of survival. The compliance would naturally have to be balanced towards other requirements for a SOC stack, such as having thick enough steel members with sufficient equivalent chromium level for corrosion resistance.

It is well known from mechanical analysis that macroscopic mechanical response becomes more compliant, if the load is absorbed by bending instead of stretching/compression. To maximize the amount of material under bending, the interconnects should have a structure with members that are thin, curved, and slanted. The fact that lower stresses are observed in the case with corrugated interconnects in the analysis justifies this.

Therefore, designs for interconnects should aim at achieving flexibility in the direction perpendicular to the cells. When subjected to an overall vertical deformation, the slanted members tend to rotate and bend, which will result in lower stresses. Thinner and more curved members will reduce the stress further, but fabrication complexity and oxidation rate also need to be considered.

In general, a multidisciplinary approach should be taken in the design of the interconnect and the stack. Design computations should also consider the chemical, fluid flow, and thermal aspects simultaneously, in order to arrive at a more general solution.

\section{Conclusions}

In this work the long-term mechanical response is studied in 4 different generic stack designs exposed to two distinct thermal profiles representative of those of an operating SOC stack. The stack designs involved either corrugated (/pressed) interconnects or cross-shaped (/machined or etched) interconnects, representing two distinct designs with different stiffness. For each of these designs the effect of introducing a contact layer was also studied. The thermal profiles represent two ideal cases; I) Heat transport by conduction only and II) Heat transport by convection only, however tailored to have the same thermal gradients. These give rise to thermal stresses in the fuel electrode layer as well as stresses in the interface between the cell and the interconnect. Those stresses are responsible for the fracture of cells or loss of contact between the cell and interconnect, respectively. The main findings from the current investigation are summarized as follows:

i) The highest stresses in the cell-interconnect interface are reached at two critical states at $A$ ) immediately after the temperature distribution from operation is reached, and B) after cooling down to room temperature after long-term operation. The stresses in case A are primarily 
compressive stresses and at that instance less critical for the integrity of the stacks. The high compressive stresses are however found to promote the creep in the interconnect throughout the operation stage. At state B the creep deformation has caused a stress-reversal, such that equally large tensile stresses appear (compressive in state A) in the interface between the interconnect and the cell, which are a driving force for delamination between the interconnect and cell.

ii) Lower stresses in the cell-interconnect interface are found in the more compliant stack designs. I.e. the stack designs with corrugated interconnects are exposed to far smaller stresses than those with cross-shaped interconnects. Furthermore, the stresses at the interface reduces further by increasing the compliance (elastic and in creep) using contact layers. This is because of the permanent deformation by creep, and that the compliant interconnects and contact layers are more easily stretched back towards its original shape during cool down. Therefore, an effective way to minimize stresses in the cell-interconnect interface and hence reduce the risk of loss of contact is through increasing the compliance of the interconnect and contact layers.

iii) In-spite of equally large thermal gradients, significantly lower stresses are observed at the interconnect-cell interface for stacks exposed to the linear temperature gradient from convective heat transport (temperature profile II) as compared to that of conductive heat transport (temperature profile I) in all stack designs. This is due to the internal constriction to thermal expansions under temperature profile 1 with thermal gradients in multiple directions. This constriction is not present with the linear temperature profile (profile II).

iv) The two different temperature profiles influence the in-plane stresses in the fuel electrode supports similarly. Hence the in-plane stresses in the cell are higher for the temperature profile I (conductive heat transport), in particular at operational conditions (state A). At state B (after cooling down), the thermal expansion coefficient mismatch of the different materials of the stacks has a significant contribution to the stresses in the cell, and the highest stresses are reached after cooling down. Here the difference between the two temperature profiles becomes less pronounced.

v) Generally, the assembly force has a minor effect on the stresses in the interconnect-cell interface. This is because a larger portion of the load will be carried by the stiffer manifold region. 


\section{Acknowledgments}

The authors wish to thank for financial funding from the Energy Technology Development and Demonstration Program (EUDP) at the Danish Energy Agency via "Maturing SOEC", project no. 64015-0523.

\section{Appendix-1}

Homogenized elastic stiffness matrix for corrugated metallic interconnect (MPa)

$$
\boldsymbol{D}=\left[\begin{array}{cccccc}
12.6 & 4.7 & 0.8 & 0 & 0 & 0 \\
4.7 & 29.9 & 0.4 & 0 & 0 & 0 \\
0.8 & 0.4 & 0.3 & 0 & 0 & 0 \\
0 & 0 & 0 & 23.2 & 0 & 0 \\
0 & 0 & 0 & 0 & 4.8 & 0 \\
0 & 0 & 0 & 0 & 0 & 10.3
\end{array}\right]
$$

Anisotropy coefficients for corrugated metallic interconnect (unitless)

$$
\mathbf{M}=\left[\begin{array}{cccccc}
235.13 & -6.32 & -572.31 & 0 & 0 & 0 \\
-6.32 & 13.23 & -6.47 & 0 & 0 & 0 \\
-572.31 & -6.47 & 1892.10 & 0 & 0 & 0 \\
0 & 0 & 0 & 53.48 & 0 & 0 \\
0 & 0 & 0 & 0 & 580.80 & 0 \\
0 & 0 & 0 & 0 & 0 & 294.02
\end{array}\right]
$$

\section{References}

[1] Kelly SM, England DM, Mukerjee S, Weber J. Fuel cell stack having a featured interconnect element 2012, European Patent, EP1300902A2.

[2] Nakajo A, Wuillemin Z, Van herle J, Favrat D. Simulation of thermal stresses in anodesupported solid oxide fuel cell stacks. Part I: Probability of failure of the cells. J Power Sources 2009;193:203-15.

[3] Nakajo A, Mueller F, Brouwer J, Van Herle J, Favrat D. Mechanical reliability and durability of SOFC stacks. Part I: Modelling of the effect of operating conditions and design alternatives on the reliability. Int J Hydrogen Energy 2012;37:9249-68.

[4] Peksen M. 3D thermomechanical behaviour of solid oxide fuel cells operating in different environments. Int J Hydrogen Energy 2013;38:13408-18.

[5] Lin C-K, Chen T-T, Chyou Y-P, Chiang L-K. Thermal stress analysis of a planar SOFC stack. J Power Sources 2007;164:238-51.

[6] Molla TT, Kwok K, Frandsen HL. Efficient modeling of metallic interconnects for thermomechanical simulation of SOFC stacks: Homogenized behaviors and effect of contact. Int J Hydrogen Energy 2016;41:6433-44.

[7] Greco F, Frandsen HL, Nakajo A, Madsen MF, Van herle J. Modelling the impact of creep on the probability of failure of a solid oxide fuel cell stack. J Eur Ceram Soc 2014;34:2695-2704.

[8] Blum L. An Analysis of Contact Problems in Solid Oxide Fuel Cell Stacks Arising from Differences in Thermal Expansion Coefficients. Electrochim Acta 2017;223:100-8.

[9] Donahue WJ, Kwon OH, Mahoney FM, Pietras JD. SOFC stack having a high temperature

This article is protected by copyright. All rights reserved. 
bonded ceramic interconnect and method for making same, US Patent, US8771901B2, 2014.

[10] Nakajo A, Wuillemin Z, Van herle J, Favrat D. Simulation of thermal stresses in anodesupported solid oxide fuel cell stacks. Part II: Loss of gas-tightness, electrical contact and thermal buckling. J Power Sources 2009;193:216-26.

[11] Nakajo A, Mueller F, Brouwer J, Van herle J, Favrat D. Mechanical reliability and durability of SOFC stacks. Part II: Modelling of mechanical failures during ageing and cycling. Int J Hydrogen Energy 2012;37:9249-68.

[12] Peksen M. 3D transient multiphysics modelling of a complete high temperature fuel cell system using coupled CFD and FEM. Int J Hydrogen Energy 2014;39:5137-47.

[13] Peksen M. Numerical thermomechanical modelling of solid oxide fuel cells. Prog Energy Combust Sci 2015;48:1-20.

[14] Pianko-oprych P, Zinko T, Jaworski Z. A Numerical Investigation of the Thermal Stresses of a Planar Solid Oxide Fuel Cell, Mater 2016; 9(10):814.

[15] Kwok K, Boccaccini D, Persson ÅH, Frandsen HL. Homogenization of steady-state creep of porous metals using three-dimensional microstructural reconstructions. Int J Solids Struct 2016;78-79:38-46.

[16] Tsuda M, Takemura E, Asada T, Ohno N, Igari T. Homogenized elastic-viscoplastic behavior of plate-fin structures at high temperatures: Numerical analysis and macroscopic constitutive modeling. Int J Mech Sci 2010;52:648-56.

[17] Molla TT, Kwok K, Frandsen HL. Transient deformational properties of high temperature alloys used in solid oxide fuel cell stacks. J Power Sources 2017;351.

[18] ThyssenKrupp VDM. Crofer 22 APU, Material Data Sheet No. 4046, May 2010 Edition 2010.

[19] Frandsen HL, Makowska M, Greco F, Chatzichristodoulou C, Ni DW, Curran DJ, Strobl M, Kuhn LT, Hendriksen PV. Accelerated creep in solid oxide fuel cell anode supports during reduction. J Power Sources 2016;323:78-89.

[20] Ni D-W, Charlas B, Kwok K, Molla TT, Hendriksen PV, Frandsen HL. Influence of temperature and atmosphere on the strength and elastic modulus of solid oxide fuel cell anode supports. J Power Sources 2016;311:1-12.

[21] Chiu Y-T, Lin C-K, Wu J-C. High-temperature tensile and creep properties of a ferritic stainless steel for interconnect in solid oxide fuel cell. J Power Sources 2011;196:2005-12.

[22] Boccaccini DN, Frandsen HL, Sudireddy BR, Blennow P, Persson ÅH, Kwok K, et al. Creep behaviour of porous metal supports for solid oxide fuel cells. Int J Hydrogen Energy 2014.

[23] Boccacini D, Sevecek O, Dlouhy I, Molin S, Charlas B, Frandsen H, Cannio M, Hjelm J, Hendriksen PV, Investigation of the bonding strength and bonding mechanisms of SOFCS interconnector-electrod interfaces' Mater Let 2016;162:250-253.

[24] Lein HL, Wiik K, Einarsrud MA, Grande T, Lara-Curzio E. High-temperature creep behavior of mixed conducting la0.5Sr 0.5Fe1-xCoxO3-8 $(0.5 \leq x \leq 1)$ materials. J Am Ceram Soc 2006;89:2895-8.

[25] Lakki A, Herzog R, Weller M, Shuber H, Reetz C, Goerke O, et al. Mechanical loss, creep, difusion and ionic conductivity of ZrO2-8 mol\%Y2O3 polycrystals 2000;20:285-96.

[26] Laurencin J, Delette G, Usseglio-Viretta F, Di lorio S. Creep behaviour of porous SOFC electrodes: Measurement and application to Ni-8YSZ cermets. J Eur Ceram Soc 2011;31:1741- 
52.

[27] Liu X, Martin CL, Bouvard D, Di lorio S, Laurencin J, Delette G. Strength of Highly Porous Ceramic Electrodes. J Am Ceram Soc 2011;94:3500-8.

\section{Tables}

Table 1: Materials and thickness of each layer in the repeating units of stack concepts

\begin{tabular}{ccc}
\hline Layer & Material & Thickness $/ \boldsymbol{\mu m}$ \\
\hline \multirow{2}{*}{ Interconnect } & Corrugated Crofer22APU & \multirow{2}{*}{800} \\
\cline { 2 - 3 } & Cross-shaped Crofer22APU & 800 \\
\hline Oxygen electrode contact layer & $90 \%$ porous 8YSZ & 200 \\
\hline Fuel electrode contact layer & $90 \%$ porous Ni & 200 \\
\hline Spacer & Crofer 22 APU & 800 or 1400 \\
\hline Cathode & $46 \%$ porous LSCF & 30 \\
\hline Electrolyte & 8 YYS & 10 \\
\hline Anode & $37 \%$ porous Ni-8YSZ & 15 \\
\hline Support & $37 \%$ porous Ni-3YSZ & 320 \\
\hline
\end{tabular}

Table 2: Material parameters for each layer.

\begin{tabular}{|c|c|c|c|c|c|c|}
\hline \multirow{2}{*}{ Material } & \multirow{2}{*}{$\begin{array}{c}\text { Young's } \\
\text { modulus / } \\
\text { GPa }\end{array}$} & \multirow{2}{*}{$\begin{array}{l}\text { Poisson's } \\
\text { ratio }\end{array}$} & \multicolumn{2}{|c|}{ Creep parameters } & \multirow{2}{*}{$\begin{array}{c}\text { Thermal } \\
\text { expansion } \\
\text { coefficient / } \\
\mathbf{K}^{-1}\end{array}$} & \multirow{2}{*}{$\begin{array}{c}\text { References/ } \\
\text { Remarks }\end{array}$} \\
\hline & & & $A / h^{-1}$ & $n$ & & \\
\hline Crofer 22 APU & 90 & 0.30 & 5.01 e-10 & 2.3 & 11.9 e-6 & {$[21,22]$} \\
\hline $\begin{array}{l}\text { Cross-shaped } \\
\text { Crofer } 22 \text { APU }\end{array}$ & 22 & 0.18 & 6.25 e-09 & 2.3 & 11.9 e-6 & $\begin{array}{l}\text { Homogenized } \\
\text { elastic and } \\
\text { creep } \\
\text { parameters }\end{array}$ \\
\hline $\begin{array}{l}\text { Corrugated } \\
\text { Crofer } 22 \text { APU }\end{array}$ & - & - & $5.01 \mathrm{e}-10$ & 2.3 & 11.9 e-6 & $\begin{array}{l}\text { Homogenized } \\
\text { elastic stiffness }\end{array}$ \\
\hline $90 \%$ porous $\mathrm{Ni}$ & 0.07 & 0.30 & 1.17 e-01 & 3.2 & 13.0 e-6 & [7] \\
\hline $90 \%$ porous $8 Y S Z$ & 0.06 & 0.29 & $2.31 \mathrm{e}-05$ & 1.0 & 10.8 e-6 & [7] \\
\hline $46 \%$ porous LSCF & 13.0 & 0.31 & 4.57 e-09 & 1.7 & 15.3 e-6 & {$[7,24]$} \\
\hline $8 Y S Z$ & 140.0 & 0.29 & 6.44 e-11 & 1.0 & 10.8 e-6 & {$[7,25]$} \\
\hline $\begin{array}{c}37 \% \text { porous } \mathrm{Ni}- \\
8 \mathrm{YSZ}\end{array}$ & 36.0 & 0.29 & 8.67 e- 08 & 1.7 & 12.8 e-6 & {$[7,26]$} \\
\hline $\begin{array}{c}37 \% \text { porous } \mathrm{Ni}- \\
\text { 3YSZ }\end{array}$ & 55.0 & 0.29 & $9.51 \mathrm{e}-08$ & 1.7 & 12.8 e- 6 & {$[7,26,27]$} \\
\hline
\end{tabular}

This article is protected by copyright. All rights reserved. 


\section{University Library}

\section{- M M I N E R VA A gateway to Melbourne's research publications}

Minerva Access is the Institutional Repository of The University of Melbourne

Author/s:

Molla, TT;Kwok, K;Frandsen, $\mathrm{HL}$

Title:

Modeling the Mechanical Integrity of Generic Solid Oxide Cell Stack Designs Exposed to Long-term Operation

Date:

2019-02-01

Citation:

Molla, T. T., Kwok, K. \& Frandsen, H. L. (2019). Modeling the Mechanical Integrity of Generic Solid Oxide Cell Stack Designs Exposed to Long-term Operation. Fuel Cells, 19 (1), pp.96-109. https://doi.org/10.1002/fuce.201800081.

Persistent Link:

http://hdl.handle.net/11343/284919 